\title{
Depression influence on memory and executive functions in patients with post-traumatic stress disorder, victims of the army conflict in Colombia.
}

\author{
Hurtado-González $\mathrm{CA}^{* 1}$, Álzate Vivas $\mathrm{D}^{2}$, Riascos Flor $\mathbf{H}^{3}$, García-Borrero $\mathbf{J J}^{4}$, Arango $\mathbf{P M}^{5}$, \\ SEMINEC ${ }^{6}$, Sánchez-Romero $\mathbf{J}^{7}$, Cifuentes-Marmolejo $\mathbf{J S}^{8}$, Hernández $\mathrm{D}^{9}$, Ramos $\mathbf{G}^{10}$, CINEPSIS ${ }^{11}$, \\ Carbonell $D^{12}$, Hernández VA ${ }^{13}$
}

${ }^{1}$ Researcher, Doctor and Professor, Psychology School, Universidad Cooperativa de Colombia sede Cali, Researcher Doctor and Professor, School of Medicine, Specialty of Psychiatry, Universidad Libre sede Cali-Colombia

${ }^{2}$ Resident doctor and Researcher, Specialty of Psychiatry, School of Medicine, Universidad Libre-Cali Colombia

${ }^{3}$ Researcher monitor, Psychology School, Universidad Cooperativa de Colombia sede Cali

${ }^{4}$ Researcher monitor, School of Medicine, Universidad Libre Cali- Colombia

${ }^{5}$ Neurosurgeon-Researcher, Universidad del Valle Cali-Colombia, University Toronto -Canadá

${ }^{6}$ Research Team on Basic and Applied Clinical Neurosciences, School of Psychology. Universidad Cooperativa de Colombia sede Cali

${ }^{7}$ Director of Physiotherapy Program, María Cano University Foundation, Bogota Colombia

${ }^{8}$ Research monitor, School of Medicine, Universidad Libre Cali-Colombia.

${ }^{9}$ Medical psychiatrist, School of Medicine, Universidad Libre-Cali-Colombia

${ }^{10}$ Neurologist, Universidad Nacional Autónoma de México

${ }^{11}$ Research Team on Psychiatry, School of Medicine, Universidad Libre, Cali-Colombia

${ }^{12}$ Doctor, Master Degree in Epidemiology, School of Medicine, Universidad Libre, Sede Cali

${ }^{13}$ Public Health Group, Iberoamerican University Corporation

\begin{abstract}
Introduction: Post traumatic Stress Disorder (PTSD) is a neuropsychiatric pathology. It is characterized by the fact that the subject has been exposed to stressful situations which have caused them physical, emotional and mental instability in different aspects of their daily life. The subjects diagnosed with PTSD show a clinical picture of severe depression which is related to a deficit in their neurocognitive functioning, especifically in memory tasks (operative memory and inmediate verbal memory) and in executive functions (semantic verbal fluency, inhibition, planning and control of their immediate conduct).

Objective: To indentify the influence of depression on memory and the executive functioning in patients with PTSD who are victims of the army conflict in Colombia.

Methodology: Participants: 50 people diagnosed with PTDS, depression, and without dementia (35 men and 15 women) participated in this study. The individuals were enlisted from the unit of victims affiliated with the municipality of Palmira, Valle del Cauca, Colombia in a period of time from 2015 through 2017, and a control group of 50 healthy subjects with the objective to compare the results and be able to establish differences and intra-group robust results.

Results: Individuals with PTSD show a higher depressive symptomatology than the ones in the control group. It was found that depression is related to the deficit in the immediate verbal memory, operative memory, and the executive functions in subjects with PTSD victims of the army conflict in Colombia.
\end{abstract}




\begin{abstract}
Conclusion: It is necessary to make plans for functional neurorehabilitation for individuals diagnosed with PTSD in order to improve their quality of life and to slow down their clinical picture to a posttraumatic dementia diagnose. The government needs to create mental health policies designed to counteract this neuropsychiatric pathology ;our main goal and the neurocognitive functioning, neurobehavioral/emotional, individual, and family neurorehabilitation of people with PTSD victims of the army conflict in Colombia, thus preventing clinical pictures of post-traumatic alexithymia.
\end{abstract}

Keywords: Depression, Executive functioning, Memory, PTSD.

Accepted on June 20, 2019

\section{Introduction}

Post traumatic stress disorder (PTSD) is a neuropsychiatric pathology which is characterized by the subject's exposition to stressful situations which have caused physical, emotional, and mental instability in many daily aspects of their lives [1-4]. PTSD is clinically correlated with the anxiety disorder according to the DSM IV [5] y DSM V [6], it can show tachycardia, thorax constriction, perspiration, nightmares, insomnia and episodes of intrusive memories concerning to the trauma that the subjects have experienced $[7,8]$.

Neuroconductual alterations as depression in the PTSD are characterized by feelings of disability, weeping, inability to experience pleasure, and bad mood which prevents the subjects from doing their daily life activities $[9,10]$.

Depression as a neurophychiatric pathology has an effect on quality of life deterioration (QOL) and on the neurocognitive functioning of people with this pathology. The data obtained by different [11-15] researches have found that depressive symptomatology affects the storage, consolidation and evocation of information, specifically on the inmediate verbal memory and in every aspect of it, likewise; it was found that depression is related to executive deficits [16-18], associated to the subcortical and the prefrontal cortex, frontal interactions, preventing the patients from regulating their decission making in different contexts, data which is also related to a clinical profile of severe cortical subcortical atrophy [19-21].

Damage has been found on the dorsolateral cortex, superior orbitofrontal gyrus, entorhinal cortex and hippocampal dentate gyrus, it prevents the patients with PTSD from correctly processing the enviromental stimulii which are present in their inmediate context, it is clinically correlated with post traumatic alexithymia [22,23].

At the end of the article a treatment suggestion on functional neurorehabilitation is presented in order to improve the QOL in people diagnosed with PTSD.

\section{Objective}

Identify the influence of depression on memory, and executive functions, in patients with PTSD victims in the Colombia army conflict.

\section{Method}

\section{Participants}

50 people diagnosed with PTSD, with depression, and with no dementia (35 men and 15 women) participated in this study. The subjects were recruited at the unit of victims assigned to the mayor's office of Palmira-Valle del Cauca in Colombia, during a period of time from 2015-2017, and in a controlled group of 50 healthy individuals in order to compare the results, and be able to establish robust data (Table 1).

To be admitted in the study, the subjects must fulfill the following requirements of inclusion:

\section{Group 1}

- Aged between 45 years to 75 years.

- Six-year education level as minimum

- To be diagnosed with PTSD by a specialist doctor in Neurology or/and with a Ph. D in Clinical Neuropsychology.

- Do not suffer from dementia:

- Obtain a score equal or higher to 27 in the Mini Mental MMSE

- Obtain a score equal or higher to 135 on the Dementia Rating Scale.

- Do not show more than ten years of evolution of the disease.

- Do not show a record of neurological, neuropsychological nor psychopathological alterations clinically demonstrable.

- Do not show a medical profile with a record in alcohol or toxic substances.

- Subjects must not have been subjected to any type of functional neuronal surgery or any treatment for neurophychiatric diseases. 
Depression influence on memory and executive functions in patients with post-traumatic stress disorder, victims of the army conflict in Colombia

Subjects in the control group had to fulfill the same requirements as the experimental one, apart from the one which states that they did not have to be diagnosed with PTSD.

Table 1. Sociodemographic characteristics of the sample.

\begin{tabular}{|c|c|c|c|c|c|c|}
\hline \multirow[b]{2}{*}{ VARIABLES } & & \multirow[b]{2}{*}{ Group with PTSD } & \multirow[b]{2}{*}{ Control group } & \multicolumn{3}{|l|}{ Contrast test } \\
\hline & & & & Valor & g.l & P-sig \\
\hline \multirow{3}{*}{ Age } & & $64,82 \pm 6,53$ & $54,73 \pm 8,43$ & \multirow{3}{*}{$\mathrm{T}=7,22$} & \multirow{3}{*}{96} & \multirow{3}{*}{, $000^{* *}$} \\
\hline & & IC $95 \%: 63,00-66,72$ & IC 95\%: $51,28-56,22$ & & & \\
\hline & & Rango: 45-75 (Mediana:65,5) & Rango: 4575(Mediana:52,0) & & & \\
\hline \multirow[t]{2}{*}{ Gender } & Men & $66,0 \%(35)$ & $39,6 \%(20)$ & \multirow[t]{2}{*}{ Chi2 $=6,71$} & \multirow[t]{2}{*}{1} & \multirow[t]{2}{*}{, $005^{* *}$} \\
\hline & Women & $34,0 \%(15)$ & $60,4 \%(30)$ & & & \\
\hline \multirow{4}{*}{ Marital state } & Married & $84,0 \%(41)$ & $84,3 \%(45)$ & \multirow{4}{*}{ Chi2 $=6,82$} & \multirow{4}{*}{3} & \multirow{4}{*}{, $092 \mathrm{NS}$} \\
\hline & Single & $5,0 \%(6)$ & $8,3 \%(4)$ & & & \\
\hline & Widower & $7,0 \%(3)$ & $2,0 \%(1)$ & & & \\
\hline & Divorced & $0 \%(-)$ & $0 \%(-)$ & & & \\
\hline \multirow{3}{*}{ Schooling } & Basic & $68,0 \%(36)$ & $37,0 \%(20)$ & \multirow{3}{*}{ Chi2 $=10,01$} & \multirow{3}{*}{2} & \multirow{3}{*}{, $002^{* *}$} \\
\hline & Medium & $22,0 \%(12)$ & $31,0 \%(18)$ & & & \\
\hline & Superior & $10,0 \%(2)$ & $32,0 \%(12)$ & & & \\
\hline
\end{tabular}

Note: ${ }^{*}$ Significant to $1 \%$. NS. No significant. PTSD. Post-traumatic Stress Disorder. g.l. Grades of liberty

\section{Materials}

For depressive symptomatology, the Geriatic Depression Rating Scale by Yesavage [24] and Beck's depression inventory (BDI) [25], were used. To evaluate the memory and the executive functions of the Dementia Rating Scale (DRS) [26], Frontal Assessment Battery. (FAB) [27], Memory item of the MMSE [28] and task of operative memory and immediate verbal memory were used.

\section{Procedure}

\section{Statistical analysis}

Difference in average, $\mathrm{T}$ of Student, Mann-Whitney $\mathrm{U}$ test, Rho Spearman's.

\section{Results}

Table 2 shows the results of the statistical test used. In both tests (BDI and Yesavage) the patients with PTSD show a superior average rating scale to the one obtained by control group.

Meaningful statistical differences were found between the two groups in the rating obtained on the rating scale of Yesavage and BDI $\mathrm{p}<0.001$ (BDI: $\mathrm{T}=16,41 ; \mathrm{p}=0.000$ y Yesavage:
$\mathrm{T}=17.12 ; \mathrm{p}=0.000)$, these data are confirmed in the test of Mann-Whitney $(\mathrm{Z}=8.48 ; \mathrm{p}=0.000$ y $\mathrm{Z}=8.30 ; \mathrm{p}=0.000)$.

In both instruments the patients with PTSD show a very high average in comparison to the one of the control group.

Table 3 shows the summary of the results of the T-student about the variables that were used to evaluate memory in different sections, followed by the results of the $U$ of MannWhitney results. Highly meaningful differences with $p<.001$ were found in each one of the memory components and minor value of the average in the subjects with PTSD compared to the control group.

MMSE memory: $T=-10.86 ; p=0.000$ y MW: $Z=-7.48 ; p=0.000$

Inmediate verbal memory: $\mathrm{T}=-7.28 ; \mathrm{p}=0.000$ y $\mathrm{MW}: \mathrm{Z}=-6.24$; $\mathrm{p}=0.000$

Differred verbal memory: $\mathrm{T}=-9.34 ; \mathrm{p}=0.000$ y $\mathrm{MW}: \mathrm{Z}=-8.32$; $\mathrm{p}=0.000$

DRS memory: $T=-5.18 ; p=.000$ y MW: $Z=-5.78 ; p=0.000$

Operative memory: $\mathrm{T}=-7.27 ; \mathrm{p}=0.000$ y $\mathrm{MW}: \mathrm{Z}=-6.32$; $\mathrm{p}=0.000$

Clock memory test: $\mathrm{T}=-7.69 ; \mathrm{p}=0.000$ y $\mathrm{MW}: \mathrm{Z}=-7.28$; $\mathrm{p}=0.000$ 
Table 2. Difference of averages. Emotional alterations: depression PTSD/Normal.

\begin{tabular}{|c|c|c|c|c|c|c|c|c|c|c|c|}
\hline \multirow{2}{*}{ Variables } & & \multirow{2}{*}{$\mathbf{N}$} & \multirow{2}{*}{ Averages \pm DS } & \multirow{2}{*}{ IC Difference To $95 \%$} & \multicolumn{5}{|c|}{ Contraste test } & \multirow{2}{*}{\multicolumn{2}{|c|}{$\begin{array}{l}\text { Size of the } \\
\text { Cohen's effect } R^{2} \\
\text { D }\end{array}$}} \\
\hline & & & & & Student-T & gl & p-Sig & $\begin{array}{l}\text { M-W } \\
\text { Sig }\end{array}$ & p- & & \\
\hline \multirow{2}{*}{ BDI } & PTSD & 50 & $18,11 \pm 6,41$ & 15,44 & \multirow{2}{*}{16,41} & \multirow{2}{*}{96} & \multirow{2}{*}{, $000^{* *}$} & \multirow{2}{*}{, $000^{* *}$} & \multirow{2}{*}{\multicolumn{2}{|c|}{3,21}} & \multirow{2}{*}{,736 } \\
\hline & Normal & 50 & $2,67 \pm 1,73$ & $(13,53-17,32)$ & & & & & & & \\
\hline \multirow{2}{*}{ Yesavage } & PTSD & 50 & $13,72 \pm 4,50$ & 11,47 & \multirow{2}{*}{17,12} & \multirow{2}{*}{96} & \multirow{2}{*}{, $000^{* *}$} & \multirow{2}{*}{, $000^{* *}$} & \multirow{2}{*}{\multicolumn{2}{|c|}{3,35}} & \multirow{2}{*}{,756 } \\
\hline & Normal & 50 & $2,23 \pm 1,45$ & $(10,13-12,81)$ & & & & & & & \\
\hline
\end{tabular}

Table 3. Mean Difference. Cognitive performance: compared memory PTSD/Normal.

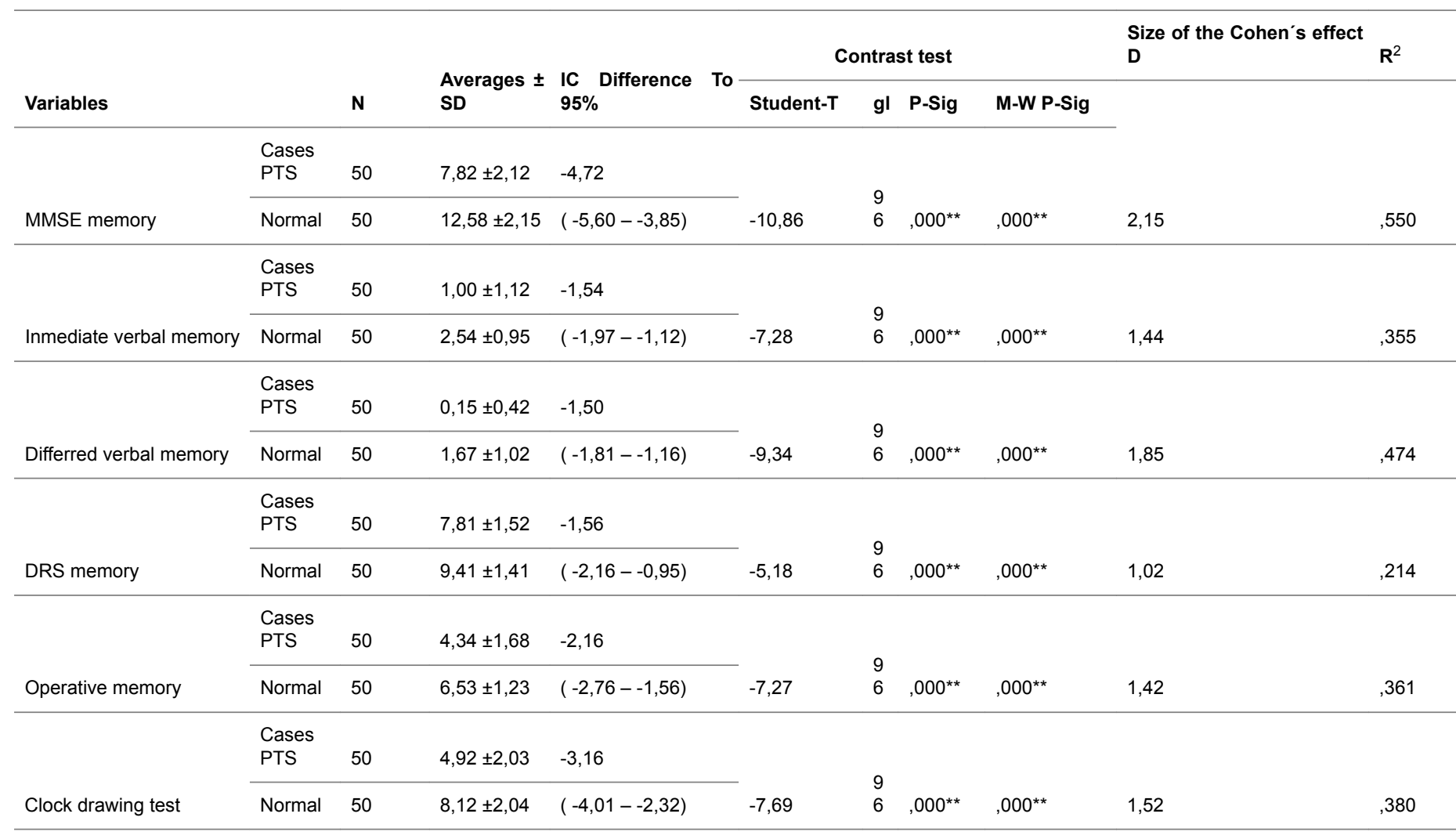

Note: ${ }^{*}$ Significant to $1 \%$. MMSE memory. Inmediate verbal memory. Differred verbal memory. DRS memory. Operative memory. Clock drawing test. PTSD. Posttraumatic Stress Disorder. SD Standard Deviation. g.I. Grades of liberty, M-W: Mann-Whiney.

The Table 4 shows the values evaluated in each one of the domains of the executive functions. Minor average values were found in the subjects with PTSD compared to the control Group subjects. Difference have been highly meaningful with $\mathrm{p}<0.001$ in each one of the sections.

FAB: $\mathrm{T}=-12.54 ; \mathrm{p}=.000$ y $\mathrm{MW}: \mathrm{Z}=-8.25 ; \mathrm{p}=.000$

Motor planning: $\mathrm{T}=-10.08 ; \mathrm{p}=.000$ y $\mathrm{MW}: \mathrm{Z}=-8.47 ; \mathrm{p}=.000$

Semantic verbal fluency: $\mathrm{T}=-5.32 ; \mathrm{p}=.000$ y $\mathrm{MW}: \mathrm{Z}=-6.71 ; \mathrm{p}=$. 000
Task change: $\mathrm{T}=-7.75 ; \mathrm{p}=.000$ y $\mathrm{MW}: \mathrm{Z}=-7.62 ; \mathrm{p}=.000$

Alternative verbal fluency: $\mathrm{T}=-8.18 ; \mathrm{p}=.000$ y $\mathrm{MW}: \mathrm{Z}=-6.32$; $\mathrm{p}=.000$

Action verbal fluency: $T=-10.75 ; p=.000$ y $M W: Z=-7.42 ; p=$. 000

Initiation/Perseveration $\quad$ DRS: $\quad \mathrm{T}=-5.94 ; \quad \mathrm{p}=.000 \quad \mathrm{y} \quad \mathrm{MW}$ : $\mathrm{Z}=-5.48 ; \mathrm{p}=.000$ 
Depression influence on memory and executive functions in patients with post-traumatic stress disorder, victims of the army conflict in Colombia

Conceptualization DRS: $\mathrm{T}=-2.43 ; \mathrm{p}=.000$ y MW: $\mathrm{Z}=-3.25 ; \mathrm{p}=.000$

Tabla 4. Difference in average. Compared executive functions PTSD/Normal.

\begin{tabular}{|c|c|c|c|c|c|c|c|c|c|c|}
\hline \multirow[b]{2}{*}{ Variables } & & \multirow[b]{2}{*}{$\mathbf{N}$} & \multirow{2}{*}{$\begin{array}{l}\text { Average } \pm \\
\text { S.D }\end{array}$} & \multirow[b]{2}{*}{ IC Difference to } & \multicolumn{4}{|c|}{ Contrast test } & \multirow[t]{2}{*}{$\begin{array}{l}\text { Size of } \\
\text { the } \\
\text { Cohen's } \\
\text { effect } D\end{array}$} & \multirow[t]{2}{*}{$\mathbf{R}^{2}$} \\
\hline & & & & & Student-T & gl & P-Sig & M-W P-Sig & & \\
\hline & $\begin{array}{l}\text { Cases } \\
\text { PTS }\end{array}$ & 50 & $9,11 \pm 1,52$ & $-2,77$ & & & & & & \\
\hline \multirow[t]{2}{*}{ FAB executive functions } & Normal & 50 & $\begin{array}{l}11,83 \\
\pm 0,35\end{array}$ & $(-3,21--2,32)$ & $-12,54$ & 96 &, $000^{\star *}$ &, $000^{* *}$ & 2,55 & ,620 \\
\hline & $\begin{array}{l}\text { Cases } \\
\text { PTS }\end{array}$ & 50 & $1,80 \pm 0,84$ & $-1,14$ & & & & & & \\
\hline \multirow[t]{2}{*}{ Motor planning } & Normal & 50 & $2,94 \pm 0,12$ & $(-1,38--0,94)$ & $-10,08$ & 96 &, $000^{* *}$ &, $000^{\star *}$ & 2,07 &, 515 \\
\hline & $\begin{array}{l}\text { Cases } \\
\text { PTS }\end{array}$ & 50 & $5,13 \pm 0,97$ & $-0,79$ & & & & & & \\
\hline \multirow[t]{2}{*}{ Semantic verbal fluency } & Normal & 50 & $5,92 \pm 0,26$ & $(-1,06--0,49)$ & $-5,32$ & 96 &, $000^{* *}$ &, $000^{\star *}$ & 1,08 & ,227 \\
\hline & $\begin{array}{l}\text { Cases } \\
\text { PTS }\end{array}$ & 50 & $2,12 \pm 0,78$ & $-0,85$ & & & & & & \\
\hline \multirow[t]{2}{*}{ Task change } & Normal & 50 & $3,00 \pm 0,00$ & $(-1,07--0,63)$ & $-7,75$ & 96 &, $000^{* *}$ &, $000^{* *}$ & 1,59 & ,385 \\
\hline & $\begin{array}{l}\text { Cases } \\
\text { PTS }\end{array}$ & 50 & $5,16 \pm 1,76$ & $-2,68$ & & & & & & \\
\hline \multirow[t]{3}{*}{ Alternative verbal fluency } & Normal & 50 & $7,80 \pm 1,42$ & $(-3,31--2,04)$ & $-8,18$ & 96 &, $000^{\star *}$ &, $000^{\star *}$ & 1,68 & ,411 \\
\hline & $\begin{array}{l}\text { Cases } \\
\text { PTS }\end{array}$ & 50 & $9,91 \pm 3,00$ & $-7,36$ & & & & & & \\
\hline & Normal & 50 & $\begin{array}{l}17,23 \\
\pm 3,70\end{array}$ & $(-8,72--5,98)$ & $-10,75$ & 96 &, $000^{* *}$ &, $000^{* *}$ & 2,21 &, 548 \\
\hline Action verbal fluency & $\begin{array}{l}\text { Cases } \\
\text { PTS }\end{array}$ & 50 & $\begin{array}{l}34,84 \\
\pm 1,36\end{array}$ & $-1,44$ & & & & & & \\
\hline \multirow[t]{2}{*}{ Initiation/Perseveration DRS } & Normal & 50 & $\begin{array}{l}36,24 \\
\pm 0,95\end{array}$ & $(-1,92--0,96)$ & $-5,94$ & 96 &, $000^{\star \star}$ &, $000^{\star *}$ & 1,23 & ,268 \\
\hline & $\begin{array}{l}\text { Cases } \\
\text { PTS }\end{array}$ & 50 & $\begin{array}{l}37,73 \\
\pm 1,28\end{array}$ & $-0,58$ & & & & & & \\
\hline Conceptualization DRS & Normal & 50 & $\begin{array}{l}38,31 \\
\pm 1,10\end{array}$ & $(-1,06--0,12)$ & $-2,43$ & 96 &, $000^{* *}$ &, $000^{* *}$ & 0,51 &, 057 \\
\hline
\end{tabular}

Note. ${ }^{* *}$ Significant to $1 \%$. Executive functions-FAB. Motor planning. Semantic verbal fluency. Task change/inhibition. Alternative and action fluency. DRS Initiation/ perseveration. DRS-conceptualization. PTSD Post-traumatic stress disorder. SD estándar deviation. Gl grades of liberty. M-W Mann-Whiney.

\section{Correlations between subjects with TEPD}

Table 5 shows some tendency to a negative, or inverse correlation, in the coefficients of Pearson and Spearman between the overall rating obtained on the BDI scale, and the rating obtained on the DRS $(p=.036)$. Nevertheless, it does not reach a significative statiscal grade $(\mathrm{p}<.005)$ when distortive elements such as schooling, and age situation which is similar in each one of the memory components, where positive statistical differences, that show the existence of any type of inverse correlation, were found.
Table 6 shows the results on the scale of Yesavage with each one of the domains, or evaluated memory sections in subjects with PTSD. Likewise, in relation to the BDI, a tendency to show negative or inverse associations were found, especially in the immediate verbal memory (.034). In the partial coefficient, and eliminating the distortive elements of schooling and age, this statistical significance disappears $(p>.05)$. Statistics that show inverse Co-relation between depression (Yesavage) and memory. 
Table 5. Correlated Analysis. Depression - BDI memory.

\begin{tabular}{|c|c|c|c|c|c|c|c|c|}
\hline \multicolumn{9}{|c|}{ Correlated variables $(\mathrm{N}=50)$} \\
\hline & & $\mathbf{R}$ & $\mathbf{P}$ & $\mathbf{R}_{\mathrm{S}}$ & $\mathbf{P}$ & $\mathbf{R}$ partial & $\mathbf{P}$ & $\mathbf{R}^{2}$ \\
\hline \multirow{6}{*}{ BDI Depression } & MMSE memory &,- 219 &, $063 \mathrm{NS}$ &,- 256 &, $070^{*}$ &,- 063 &, 335 NS &, 004 \\
\hline & $\begin{array}{l}\text { Inmediate verbal } \\
\text { memory }\end{array}$ &,- 220 &, $063 \mathrm{NS}$ &,- 203 &, $078 \mathrm{NS}$ &,- 055 &, 356 NS &, 003 \\
\hline & $\begin{array}{l}\text { Differred verbal } \\
\text { memory }\end{array}$ &,- 066 &, $325^{N S}$ &,- 002 &, $495^{N S}$ &, 025 &, 434 NS &, 001 \\
\hline & Operative memory &, 005 &, 485 NS &,- 035 &, 404 NS & 079 & ,298 NS &, 006 \\
\hline & Clock drawing test &,- 049 &, $368^{N S}$ &,- 112 &, 219 NS & ,105 &, 239 NS & ,011 \\
\hline & DRS memory & 130 &, $185^{\mathrm{NS}}$ & ,008 &, $036^{*}$ &, 172 &, $121 \mathrm{NS}$ &, 030 \\
\hline
\end{tabular}

Note: NS: Non-Significant; BDI: Beck's Depression inventory; MMSE memory; Inmediate Verbal Memory; Differred verbal memory Operative ; Clock drawing test; DRS memory; R: Pearson's co-relation;RS: Spearman Co-relation

Table 6. Correlated Analysis. Depression withmemory.

\begin{tabular}{|c|c|c|c|c|c|c|c|c|c|}
\hline \multicolumn{3}{|c|}{ Correlated variables $(\mathrm{N}=50)$} & \multirow{2}{*}{$\begin{array}{l}\mathbf{R} \\
-, 287\end{array}$} & \multirow{2}{*}{$\begin{array}{l}\mathbf{P} \\
, 076\end{array}$} & \multirow{2}{*}{$\frac{\mathbf{R}_{\mathrm{S}}}{-, 435}$} & \multirow{2}{*}{$\begin{array}{l}\mathbf{P} \\
, 084\end{array}$} & \multirow{2}{*}{$\begin{array}{l}\text { R partial } \\
-, 180\end{array}$} & \multirow{2}{*}{$\begin{array}{l}\mathbf{P} \\
, 110^{\mathrm{NS}}\end{array}$} & \multirow{2}{*}{$\begin{array}{l}\mathbf{R}^{2} \\
, 032\end{array}$} \\
\hline & MMSE mem & & & & & & & & \\
\hline & $\begin{array}{l}\text { Immediate } \\
\text { memory }\end{array}$ & verbal &,- 206 &, $075^{N S}$ &,- 257 &, $034^{*}$ &,- 064 &, $332 \mathrm{NS}$ & ,004 \\
\hline \multirow{4}{*}{ Yesavage } & $\begin{array}{l}\text { Differred } \\
\text { memory }\end{array}$ & verbal &,- 109 &, 227 NS &,- 079 &, 294 NS &,- 059 &, 345 NS & ,003 \\
\hline & Operative $\mathrm{m}$ & mory & ,038 & ,397 NS &,- 006 &, 482 NS &, 092 & ,266 NS & ,008 \\
\hline & $\begin{array}{l}\text { Clock- draw } \\
\text { memory }\end{array}$ & ng test &,- 031 &, 417 NS &,- 057 &, 348 NS & ,115 &, 217 NS & ,013 \\
\hline & DRS memor & &, 023 &, 438 NS &,- 056 &, 350 NS &, 063 &, 334 NS & ,004 \\
\hline
\end{tabular}

Note: NS: Non- Significant; Yesavage; Geriatric depression inventory; MMSE Memory; Immediate verbal memory; Differred verbal memory; Operative memory. Clockdrawing test memory; DRS memory R: Pearson's co-relation; RS: Spearman's co-relation.

Table 7 shows the results of the corelations between the BID (depression) and the executive functions.

Table 7: Co-relational Analysis. Depression with executive functioning

\begin{tabular}{|c|c|c|c|c|c|c|c|c|}
\hline \multicolumn{2}{|c|}{ Correlated variables $(\mathrm{N}=50)$} & \multirow{2}{*}{$\begin{array}{l}\mathbf{R} \\
-, 277\end{array}$} & \multirow{2}{*}{$\begin{array}{l}\mathbf{P} \\
, 025^{*}\end{array}$} & \multirow{2}{*}{$\begin{array}{l}\mathbf{R}_{\mathbf{S}} \\
-, 260\end{array}$} & \multirow{2}{*}{$\begin{array}{l}\mathbf{P} \\
, 032 \text { * }\end{array}$} & \multirow{2}{*}{$\begin{array}{l}\text { R partial } \\
-, 211\end{array}$} & \multirow{2}{*}{$\begin{array}{l}\mathbf{P} \\
, 075^{\mathrm{NS}}\end{array}$} & \multirow{2}{*}{$\begin{array}{l}\mathbf{R}^{2} \\
, 045\end{array}$} \\
\hline & FAB executive functions & & & & & & & \\
\hline & Motor planning & ,123 &, 197 NS &, 031 &, $415^{N S}$ & ,152 &, 152 NS & ,023 \\
\hline \multirow{6}{*}{ BDI Depression } & Semantic verbal fluency &,- 343 &, $006^{* *}$ &,- 270 &, 028 * &,- 293 &, 022 * & 086 \\
\hline & Task change &,- 236 &, 048 * &,- 264 &, $031 *$ &,- 196 &, 091 NS & ,038 \\
\hline & Alternative verbal fluency &,- 130 &, $185^{N S}$ &,- 213 &, $069 \mathrm{NS}$ &,- 059 &, 346 NS & ,003 \\
\hline & Action verbal fluency &,- 283 &, $021 *$ &,- 283 &, 022 * &,- 265 &, 033 * & ,070 \\
\hline & Initiation/Perseveration &,- 084 &, $281 \mathrm{NS}$ &,- 045 &, $378 \mathrm{NS}$ &,- 071 &, $315^{N S}$ & ,005 \\
\hline & Conceptualization &,- 068 &, 320 NS &,- 154 & 142 NS &,- 024 &, 435 NS & 001 \\
\hline
\end{tabular}

Note: Significant to 5\%; BDI: Beck's depression inventory; FAB executive functions; Motor planning; Semantic verbal fluency; Task change /Inhibition; Action and Alternative verbal fluency; Initiation/Perseveration -DRS; Conceptualization; R: Pearson's correlation; RS: Spearman's co-relation.

A tendency to show negative or inverse corelations was found, but especifically in the overall punctuation of the $\mathrm{FAB}(\mathrm{p}<.05)$ with a semantic verbal fluency $(\mathrm{p}<.01$ en Pearson y $\mathrm{p}<.05$ en
Spearman), also with the task chance $(\mathrm{p}<.05)$ and the verbal action fluency. Subsequently, when the variable statistic controls which modulate the effect, such as age and schooling 
was done, many significative statistical differences with $\mathrm{p}<0.5$ corelations of BDI with semantic verbal fluency $(\mathrm{r}=-.293 ; \mathrm{p}=$ $022)$ and verbal action fluentcy $(r=-.265 ; \mathrm{p}=.033)$ were found.

Table 8 shows the results of Yesavage test with each one of the domains of the executive functions. Only inverse correlations were found on the overall rating scale of the FAB $(p<.05)$, semantic verbal fluentcy $(\mathrm{p}<.01)$, task change $(\mathrm{p}<.05)$ and fluentcy of verbal action $(\mathrm{p}<.05)$, meaningful statistical difference in the alternate verbal fluency section was found, but this time, only in the Spearman's coeffient $(\mathrm{p}<.05)$.

Afterwards, when the statistical control of modulating variables was made, meaningful stastitical differences are maintained with the correlations of Yesavage's test with: FAB $(\mathrm{r}=-.266, \mathrm{p}=.033)$, verbal fluentcy $(\mathrm{r}=-.380, \mathrm{p}=.003)$ and task change $(\mathrm{r}=-.246, \mathrm{p}=.046)$.

Table 8: Co-relation Analysis . Depression with executive functioning.

\begin{tabular}{|c|c|c|c|c|c|c|c|c|}
\hline & related variables $(\mathrm{N}=50)$ & $\mathbf{R}$ & $\mathbf{P}$ & $\mathbf{R}_{\mathrm{S}}$ & $\mathbf{P}$ & $\mathbf{R}$ partial & $\mathbf{P}$ & $\mathbf{R}^{2}$ \\
\hline \multirow[t]{8}{*}{ Yesavage } & Executive functions $F A B$ &,- 323 &, $011 *$ &,- 320 &, 012 * &,- 266 &, 033 * & ,071 \\
\hline & Motor planning & ,167 &, 123 NS & ,147 &, $153^{N S}$ & ,204 &, $082^{N S}$ &, 042 \\
\hline & Semantic verbal fluency &,- 421 &, $001^{* *}$ &,- 437 &, $001^{* *}$ &,- 380 &, $003^{* *}$ &, 144 \\
\hline & Task change &,- 271 &, 029 * &,- 277 &, 026 * &,- 246 &, 046 * &, 060 \\
\hline & Alternating verbal fluency &,- 142 &, 163 NS &,- 302 &, 017 * &,- 057 &, 349 NS &, 003 \\
\hline & Action verbal fluency &,- 241 &, 046 * &,- 294 &, 019 * &,- 220 &, 067 NS & ,048 \\
\hline & Initiation/Perseveration &,- 067 &, 321 NS &,- 036 &, 402 NS &,- 050 &, 358 NS &, 002 \\
\hline & Conceptualization &,- 149 &, 152 NS &,- 170 &, 118 NS &,- 108 & ,233 NS &, 012 \\
\hline
\end{tabular}

Note: * Significant. to $5 \%$ BDI: Yesavage's Depression Inventary Executive Functions-FAB.Motor planning. Semantic verbal fluentcy. Task change/inhibition. Alternating and action verbal Fluentcy. Initiation/perseveration-DRS. Conceptualization - DRS. R: Co-relation of Pearson. RS: Spearman co-relation.

\section{Conclusion}

The data obtained in this research shows that the subjects with PTSD present more depressive symptomatology than the ones in the control group.

The presence of depressive symptomatology in patients with PTSD is corelated in negative or inverse manner with the executive functioning (verbal fluency and task change), and in memory tasks, specifically in immediate verbal memory tasks.

Depression as a frequent neuroconductual alteration in PTSD affects the detriment of brain structures such as the frontalsubcortical circuits, prefrontal cortex, dorsolateral cortex, and the superior orbitofrontal gyrus; brain structures which co-related to planification, organization, decission making, and the immediate conduct control (executive functions) (Figure 1).

Likewise, the depressive symptomatology includes the inability of the subjects to evoke and process information, finding disfunction in the cell wall of the hippocampus, the amygdala nuclei, the tail of caudate nucleus, and the temporal projections of the temporal lobe (Figure 2).

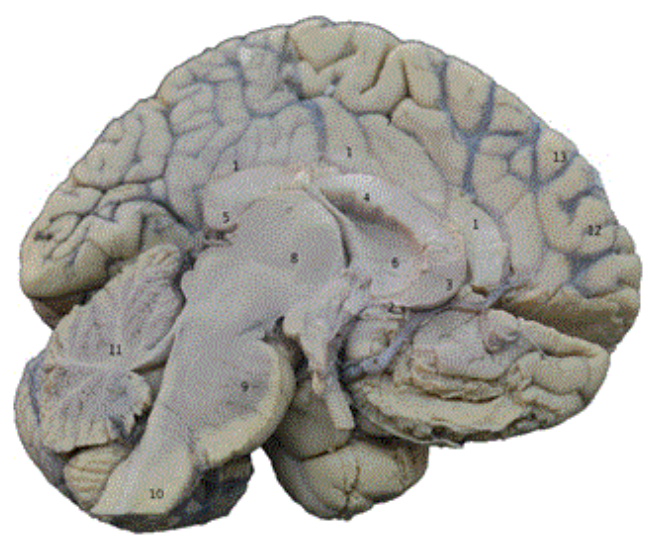

Figure 1. Mind-sagittal section: Dysfuntion/dysregulation of brain structures associated with depression in subjects with PTSD victims of the army conflict in Colombia. 1. Gyrus cingull, 2.Rostrum of corpus callosum, 2. Rostrum of of corpus callosum, 3. Genn of of corpus callosum, 4.body of of corpus callosum, 5. Splenium of of corpus callosum, 6. Cavuum of septum pellucidum, 7. Marginal callosum fissure, 8. Midbrain, 9. Protuberance, 10. Medulla oblongata, 11.Cerebellum, 12. Upper orbitofrontal gyrus, 13. Orbitofrontal cortex. Taken from Corina Brain Research. Digital Application. School of Medicine. Libre University. Clinical, Basic and Applied Neurosciences (2019).

The depressive symptomatology of the subjects with PTSD is related to the dopamine deficit located in the compact nigra pars substance of the midbrain, thus it is necessary to establish functional neurorehabilitation plans in order to improve the 
QOL of these people, and to slow down the post traumatic dementia clinical picture.

\section{Functional Neurorehabilitation treatment proposal for people with PTSD:}

During the last year, Colombia has highly advanced in different fields, nevertheless, there is a lot yet to know and search for in order to have the ability to intervene in vulnerable populations as the army conflict victims. Unfortunately, the Country is being ruled by ministers who don't have the ability to empathize with other people because of ignorance. In the midst of this, new mental health policies, which are empty and far distant from the social reality, are being created.

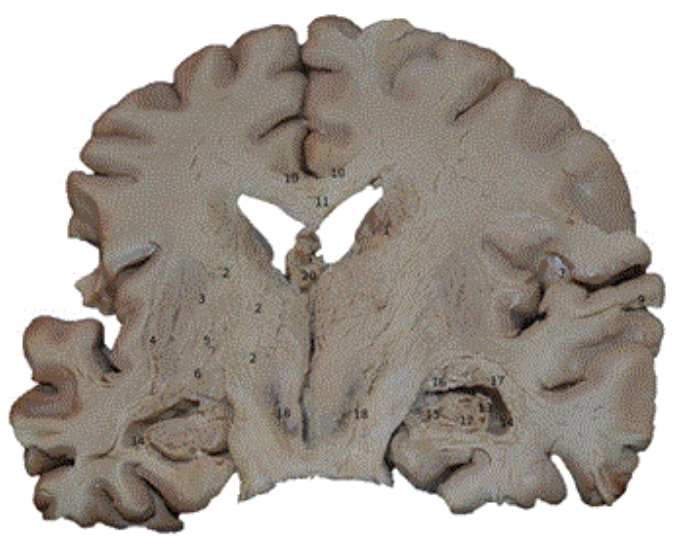

Figure 2. Coronal cut at the midbrain level. Dysfunction/ dysregulation of brain structures associated with the PTSD in victims of the army conflict in Colombia. 1. Caudate Nucleus, 2. Internal capsule, 3. Putamen, 4. Clastrum, 5. Extreme capsule, 6. External capsule, 7. Insula, 8. Lateral fissure of Silvio, 9. Temporal lobe, 10. Gyrus cinguli, 11. Corpus Callosum, 12. Hippocampus, 13.Alveus, 14. Temporal elongation of the cerebral ventricle, 15. Fimbria, 16. Complex amygdaloid nuclei, 17. Tail of caudate nucleus, 18. Compact nigra pars substantia/matter, 19. Midbrain, 20. Posterior pillars of fornix. Taken from Corina Brain Research. Digital Application. School of Medicine. Libre University. Clinical, Basic and Applied Neurosciences (2019).

We need mental Health policies that strive to improve PTSD patient's quality of life and not just a stastistical datum which is only shown on paper and in hands of people who do not know the consequences of the social phenomena, therefore we propose the following:

- Doctors must be trained and qualified to diagnose people with PTDS, because most of the diagnosis are confused with dissociatives alterations of personality or with a generalized anxiety clinical picture.

- Victims of the army conflict in Colombia require an evaluation process, diagnosis, and permanent treatement. The purpose of this is to identify neurobehavioral and neurocognitive alterations in early stages so we can slow down the possible clinical pictures of Postraumatic dementia.

- The subjects with PTDS must be individualized so that we can allow the cases to be the only ones for the Medical professional (psychiatry or neurologist), and their treatment according to the type of trauma suffered by the patient.

- Subjects with PTDS need the support of resilient communities. This is going to enable them to find a personal meaning to life and deal with other people's reality from different assertive coping strategies in their immediate context.

- It is the duty of the state to create mental health policies, specially inclusive ones, and not social inclusion processes which can be confusing or overlapped with process of social integration.

- Urgent attention patients with PTSD is an important matter for a competent health care professional, but it is more relevant for society in general, since we have the responsibility of preventing the postraumatic alexithymia.

"I wake up three or four times in the night, and I feel how the bomb explosions, the shouts of the people thunder in my mind, but above all of this, I listen to my children's shouts for help"

Account taken from a patient with PTSD

¡Thanks CMM!

\section{References}

1. Roca V, Hart J, Kimbrell T, Freeman T. Cognitive function and dissociative disorder status among veteran subjects with chronic posttraumatic stress disorder: a preliminary study. J Neuropsychiatry Clin Neurosci 2006; 18: 226-230.

2. Charlson FJ, Steel Z, Degenhardt L, Chey T, Silove D, Marnane C. Predicting the impact of the 2011 conflict in Libya on population mental health PTSD and depression prevalence and mental health service requirements. PLoS One 2012; 7: 40593.

3. Hurtado Gonzalez CA. Alteraciones neuropsicológicas en el estrés postraumático. Gredos 2011.

4. Scaer RC. The neurophysiology of dissociation and chronic disease. Appl Psychophysiol Biofeedback 2001; 26: 73-91.

5. First Michael B, A Frances, and H Pincus. "DSM-IV: Manual diagnóstico y estadístico de los trastornos mentales. Masson 1995; 401-456.

6. Vihang N. Vahia. Diagnostic and statistical manual of mental disorders 5: A quick glance. Indian J Psychiatry 2013; 55 :220-223.

7. Chiara Luoni, Massimo Agosti, Sara Crugnola, Giorgio Rossi, Cristiano Termine. Psychopathology: Dissociation and Somatic Symptoms in Adolescents Who Were Exposed to Traumatic Experiences. Front Psychol 2018; 9: 2390.

8. Briere, John. Dissociative symptoms and trauma exposure: specificity, affect dysregulation, and posttraumatic stress. J Nerv Ment Dis 2006;194:78-82.

9. Phillip A Raab, Margaret-Anne Mackintosh, Daniel F. Gros, Leslie A. Morland. Impact of comorbid depression on quality of life in male combat Veterans with posttraumatic stress disorder.JRRD 2015;52: 563-576.

10. Roberts B, Damundu EY, Lomoro O, Sondorp E. Postconflict mental health needs: a cross-sectional survey of 


\section{army conflict in Colombia}

trauma, depression and associated factors in Juba, Southern Sudan. BMC Psychiatry 2009;4:9-7.

11. Werner NS, Meindl T, Engel RR, Rsoner R, Riedel M, Reiser M. Hippocampal function during associative learning in patients with posttraumatic stress disorder. J Psychiatry Res 2009; 43: 309-318.

12. Hurtado González CA, Ríos D, De la Cruz-Cifuentes O,riviño O, BRI, Mosquera-Lemus Y,Bolaños $\mathrm{K}$, SEMINEC, Ordoñez , Gutiérrez-Lenis. Neurobehavioral disorders in a patient diagnosed with posttraumatic stress disorder and undifferentiated schizophrenia. Clinical case of low prevalence and incidence in Colombia.biomedres 2018; 29:1437-1443.

13. Zambrano-Erazo S, Guzmán-Villa DC, Hurtado-González CA, Seminec D, De la Cruz-Cifuentes, Triviño O, Olayo J. Neuropsychological abnormalities in patients diagnosed with post-traumatic stress disorder.Biomedres 2017; 28: 2609-2616.

14. Crocker LD, Keller AV, Jurick SM, Bomyea J, Hays CC, Twamley EW, Jak AJ. Mild Traumatic Brain Injury Burden Moderates the Relationship Between Cognitive Functioning and Suicidality in Iraq/Afghanistan-Era Veterans. J Int Neuropsychol Soc 2019;25:79-89.

15. Brenner LA, Betthauser LM, Homaifar BY, Villarreal E, Harwood JE, Staves PJ, Huggins JA. Posttraumatic stress disorder, traumatic brain injury, and suicide attempt history among veterans receiving mental health services. Suicide Life Threat Behav 2011;41:416-23.

16. Sophie E Holmes, Dustin Scheinost, Nicole DellaGioia, Margaret T Davis, David Matuskey,Robert H Pietrzak, Michelle Hampson, John H Krystal,Irina Esterlis. Cerebellar and prefrontal cortical alterations in PTSD: structural and functional evidence. Chronic Stress (Thousand Oaks) 2018;2.

17. Scheinost D, Holmes SE, DellaGioia N, Schleifer C, Matuskey D, Abdallah CG ,Hampson M, Krystal JH, Anticevic A, Esterlis I. Multimodal investigation of network level effects using intrinsic functional connectivity, anatomical covariance, and structure-to-function correlations in unmedicated major depressive disorder. Neuropsychopharmacology 2018;43:1119-1127.

18. Patel R, Spreng RN, Shin LM, Girard TA. Neurocircuitry models of pottraumatic stress disorder and beyond: a metaanalysis of functional neuroimaging studies. Neurosci Biobehav Rev 2012;36:2130-2142.

19. Kober H, Barrett LF, Joseph J, Bliss-Moreau E, Lindquist $\mathrm{K}$, Wager TD Functional grouping and cortical-subcortical interactions in emotion: a meta-analysis of neuroimaging studies. Neuroimage 2008;42:998-1031.
20. Reuveni I, Bonne O, Giesser R, Shragai T, Lazarovits G, Isserles M, Schreiber S, Bick AS, Levin N. Anatomical and functional connectivity in the default mode network of post-traumatic stress disorder patients after civilian and military-related trauma. Hum Brain Mapp 2016; 37: 589-599.

21. Bressan RA, Quarantini LC, Andreoli SB, Araújo C, Breen G, Guindalini C. The posttraumatic stress disorder Project in Brazil: neuropsychological, structural and molecular neuroimaging studies in victims of urban violence. BMC Psychaitry 2009; 9:30.

22. Hayes JP, Hayes SM, Mikedis AM. Quantitative metaanalysis of neural activity in posttraumatic stress disorder. Biol Mood Anxiety Disord 2012; 2:9.

23. Baldaçara L, Borgio JGF, Araújo C, Nery-Fernandes F, Lacerda ALT, Moraes WAdS, Montaño MBMM , Marlos Rocha, Quarantini LC, Aline Schoed, Mariana Pupo, Mello FM, Andreoli SB, Miranda-Scippa A, Roberto Ramos L, Mari JJ, Bressan RA, and Jackowski AP.Relationship between structural abnormalities in the cerebellum and dementia, posttraumatic stress disorder and bipolar disorder. Dementia \& Neuropsychologia 2012; 6:203-211.

24. Yesavage JA, Brink TL, Rose TL, Lum O, Huang V, Adey M, Leirer VO. Development and Validation for a Geriatric Depression Screening Scale: A Preliminary Report. Journal Psychiatry Research 1983; 17: 37 - 49.

25. Beck AT, Ward CH, Mendelson M, Mock J, Erbaugh J. An Inventory for Measuring Depression Archives of General Psychiatry. 1961; 4: 561-571.

26. Mattis, S. Dementia Rating Scale. Odessa, FL: Psychological Assessment Resources. 1988.

27. Dubois B, Slachevsky A, Litvan I, Pillon B. The FAB: a Frontal Assessment Battery at bedside. Neurology 2000; 55: 1621-1626.

28. Folstein MF, Folstein SE, McHugh PR. "Mini-mental state". A practical method for grading the cognitive state of patients for the clinician. J Psychiatr Res 1975; 12:189198.

\section{*Correspondence to}

Carlos Alberto Hurtado González

Faculty of Psychology

Cooperative University of Colombia,

Colombia

Email: carlosalbertopsi@hotmail.com 